\title{
DOSSIÊ
}

\section{PERSPECTIVAS ANTROPOLÓGICAS E \\ SOCIOLÓGICAS EM EDUCAÇÃO}

\section{ANTHROPOLOGICAL \& SOCIOLOGICAL \\ PERSPECTIVES IN EDUCATION}

\author{
Luiz Alberto Couceiro* \\ Juarez Lopes de Carvalho Filho** \\ Giuliana Franco Leal***
}

Em 1907, Franz Boas (2004) enunciava, em conferência por ele denominada "Antropologia”, que cabia aos antropólogos estudar aspectos anatômicos, fisiológicos e psicológicos das culturas, de indivíduos e dos grupos sociais os mais diversos. Barreiras geográficas não seriam motivos para o escalonamento de níveis de superioridade ou inferioridade técnicas, nem populações sem escrita seriam inferiores em algum nível às que tivessem essa possibilidade de registro. Boas observava que não haveria motivação científica, do ponto de vista da comprovação de leis universais, para perspectivas racistas nas pesquisas sobre seres humanos e seus critérios e condições ecológicas de relacionamentos, mas apenas política ${ }^{1}$.

Tais observações, aparentemente, nada têm a ver com educação, mas isso somente se procurarmos um entendimento do

*É doutor em Antropologia, professor do Departamento de Sociologia \&t Antropologia da UFMA (São Luis/MA/Brasil) e no Programa de Pós-Graduação em Ciências Ambientais e Conservação da UFRJ (Macaé/ RJ/Brasil), e um dos coordenadores do grupo de pesquisas Flutua (Fluxos \& Temporalidades em Universos Antropológicos). luizalbertocouceiro@gmail.com.

** É doutor em Sciences Sociales et Économiques, professor do Departamento de Sociologia \&t Antropologia e do Programa de Pós-Graduação em Ciências Sociais da UFMA (São Luís/MA/Brasil). juarez.lopes@gmail.com. **** É doutora em Sociologia e professora no Programa de Pós-Graduação em Ciências Ambientais e Conservação, UFRJ (Macaé/RJ/Brasil). giulianafrancoleal@yahoo.com.br.

1. Sobre esses aspectos da obra de Boas, ver seu livro anterior à palestra por nós referida (BOAS, 2010), além das observações de Moura (2004) e Stocking Jr (1992a). 
assunto seguindo uma ótica institucional mais direta. Os papéis das instituições são fundamentais na percepção que podemos ter da construção de linhas de pesquisa, temas fomentados por agências públicas e privadas, geração de material coletado em campo ou conformado em exposições em museus, influenciando a suposta racionalidade isolada do não menos suposto “cientista genial” (FLECK, 2010). Tudo isso estava nas ambições de Boas e de tantos outros cientistas sociais; e continua nas agendas da configuração de estratégias de status acadêmico ${ }^{2}$. Como se o olhar sobre educação devesse obedecer ao foco predial, arquitetônico cru, de unidades de ensino e aprendizagem; como se fossem ilhas autônomas da vida social e com significação dada em si mesma, retratos de vontades duras das burocracias e de planos de gover$n^{3}$. Ainda seguindo a perspectiva de Boas, faz-se necessário reconhecer os processos históricos - leia-se de acúmulo de experiências ao longo do tempo passado que continua presente ${ }^{4}$-, para a compreensão de situações do presente observável. Técnicas seriam investigadas em contextos processuais, destacando os perfis demográficos, ecológicos, nutricionais, em termos de semelhanças e diferenças das experiências humanas. No caso específico da obra de Boas, mais as segundas do que as primeiras (STOCKING JR., 2004).

Essas preocupações vêm sendo parte da agenda de pesquisas em educação, curiosamente pouco ligadas às reflexões de Boas, de maneira mais direta - como demonstram os balanços bibliográficos produzidos por Oliver (1992), Neves (2002), e ainda o comentário crítico de Martins (2002), além de Martins \&t Weber (2010). Contudo, não é difícil de perceber a dedicação de algumas de suas seguidoras, mais ou menos fiéis, no entendimento das técnicas de aprendizado e ensino em nada inatas, supostamente raciais, mas sim parte das formas de existir das pessoas: de Margareth Mead (1964) ao entendimento do conceito de "evolução" como processo dos critérios de conformação dos comportamentos na relação entre homem e natureza; de Ruth Benedict (2005) acerca das regularidades nas maneiras de agir, "padrões de cultura”, de pessoas e grupos por ela pesquisadas; e de Ruth Landes (2002) dos momentos-chave para a construção dos códigos sociais de autoridade

2. Sobre Boas e as suas atuações com colegas no contexto dos EUA, ver Stocking Jr. (1992b). Exemplo da importância das agências de fomento de pesquisas, ligadas à políticas governamentais, direta ou indiretamente, organizações privadas, institutos de pesquisa e centros universitários, também pode ser detalhadamente conferido em Schumaker (2001).

3. Sobre isso, ver os argumentos acerca das acusações de feitiçaria observadas pelos agentes sociais envolvidos e pelas possibilidades de inserção das mesmas no âmbito judiciário de Douglas (1963). A mesma autora tece uma série de considerações acerca da perspectiva de sucesso ou fracasso individual ante as amarras morais e éticas das instituições sociais, em Douglas (1986).

4. Essa expressão acerca da ideia de que o presente é uma colcha de retalhos elaborada pelo indivíduo, que somente faz sentido nas relações com outros indivíduos, é explorada por vários autores da assim chamada história das ideias, como White (1992), e sua proposta de avaliar as operações de estilo de escrita de autores da historiografia ainda fora dos cursos de história, ou Löwith (1992), ao avaliar os critérios de configuração da ideia de que a temporalidade possui sentido histórico, seja de ensinamento sobre o passado para a não repetição de equívocos no presente, seja para a possibilidade de salvação do presente na preparação de um futuro melhor. 
dos poderes de sacerdotes e sacerdotisas iniciados na educação mágico-religiosa em terreiros de candomblé em Salvador 5 .

Nos anos 1940 e início dos 50, Charles Wright Mills (1976) avaliou qual tipo de sociedade elencava elementos sustentados por classifıcações através da escrita, ligadas à organização de tarefas de multidões, sistematizadas em arquivos, números e contabilidades. Pessoas dedicavam-se em escritórios a trabalhar por meio de técnicas aprendidas especificamente para seus ofícios de dar sentido administrativo à vida de outras tantas por elas desconhecidas. Esse era, em certa medida, o início dos aprofundamentos do que recentemente cientistas sociais avaliam em termos de especificidades educacionais, nos níveis de treinamento na operação de sistema de produção e organização de dados, na atuação tecnocrática de funcionários dos diversos setores dos governos democráticos e na crescente tecnologia da produção e arquivamento de dados (CALLON; LASCOUMES; BARTHE, 2011; PINCH; SWEDBERG, 2008; SOUZA LIMA, 2012).

A partir de Mills, conformava-se o tipo social, com educação universitária, conceituado por "colarinho branco", e suas variáveis históricas e culturais, digamos, como as observadas por Gilberto Velho (1977;
1998), em casos no Rio de Janeiro dos anos 1960 e 70, remunerados por patrões particulares ou públicos. Valores e condutas desses agentes especializados, em trajetórias educacionais próprias de grupos sociais segmentados por oportunidades de ascensão social supostamente meritocrática ${ }^{6}$, davam mobilidade a mundos até então pouco ou nada explorados pelas ciências sociais como objetos de estudo.

Dedicado à obra de Max Weber em um grande projeto de tradução de seus textos para os EUA, juntamente a Hans Gerth, Mills (1946) aprofundava, no contexto das grandes metrópoles estadunidenses, preocupações daquele autor acerca dos critérios socialmente elaborados de carpintaria de um tipo social específico, dedicados às letras como técnicas racionais eficazes de armazenamento, processamento e transmissão de informações e conhecimento. Weber havia desenvolvido estudos sobre o que chamou de "letrados chineses" (1982) e "camadas portadoras" de responsabilidade (1996a e 1996b), no sentido ético, de gestão de recursos morais os mais diversos na política da China confucionista. Nessa mesma linha, pode-se buscar nos estudos de Robert K. Merton (1970a e b) professor na mesma universidade de Boas, Colúmbia, acerca

5. Para considerações acerca das implicações apontadas da relação entre potencialidades biológicas e culturais do homem e a sua configuração no ambiente sócio-ecológico, ver Yans-McLaughlin (1986). Para as condições sociais e acadêmicas da construção da pesquisa de Landes no contexto apontado, ver Cunha (2004). Ver, também, a coletânea de textos de Golde (1986), para uma painel das estratégias e reflexões sobre os trabalhos de campos dessas autoras por elas mesmas.

6. Aqui usamos os sentidos de formação de conjuntos de pessoas com trabalhos especializados para justificar sua ascensão econômica e o reconhecimento de potencialidades empregadas para isso a partir de Bourdieu (1979) e Boltanski (1982). Há considerações a serem observadas e muito pontuais que auxiliam na compreensão desse debate em Bourdieu \&t Boltanski (2009). Aspectos da meritocracia como ideologia na formação de recursos humanos de trabalhadores especializados tiveram como referência Schultz (1967; 1973), através de seu conceito de "capital humano". E é essa mesma teoria que vem sendo combatida por diversas pesquisas. Exemplo importante da antítese do indivíduo como gênio inato nas investigações sociológicas acerca de biografias é Elias (1994) e, acerca das formas de (auto) identificação de prestígio de um grupo universitário estabelecido como superior no meio universitário, Becker, Geer, Hugues \& Strauss (1961). 
dos critérios de financiamentos a pesquisas científicas e grupos nelas influentes, e para isso legitimados , a continuidade das preocupações de se compreender processos de consolidação de relações de poder e valores morais por meio da autorização de técnicas de classificação letrada do mundo.

0 espírito desse Dossiê, para continuarmos na referência a Weber - termo que lhe era muito caro e valioso - é buscar escapar do lugar-comum de observar, tratar de processos e situações supostamente óbvias acerca do que seja educação como tema de investigação e partir para pesquisas de olhares mais abrangentes por meio da educação.

Ao longo do processo de institucionalização da sociologia e antropologia da educação, correntes de significação nas ciências sociais buscaram entendimentos sobre educação, tanto em termos institucionais, políticas públicas, mobilidade urbana, como em conformação de grupos em classe, estamentos e status. Desde os anos 1960, coletâneas de autores nacionais e estrangeiros vêm sendo publicadas no Brasil, bem como importantes balanços críticos da produção especializada produzidos recentemente (PEREIRA, 1967; FORACCHI; PEREIRA, 1976). São leituras que informaram os estudos acerca da educação, marcadamente até os anos 1990, sendo instrumentalizadas por cientistas sociais, em larga medida sociólogos, e que vêm sendo operadas sob novas perspectivas conceituais e metodológicas que buscam enfatizar o papel de entendimentos dos agentes sociais acerca de educação fora do campo mais abstrato, não somente aceitando-a, como também reivindicando-a, dela duvidando e sendo parte constitutiva ${ }^{7}$.
Nesse sentido, autores e linhas analíticas tradicionais são revisitados, em pesquisas de campo realizadas com outras chaves interpretativas. Operando através das instituições de ensino, e não nelas, esse dossiê se propõe, de maneira provocativa, a publicar pesquisas recentes e desafiadoras em Sociologia e Antropologia através da educação. Nós, bem como os autores colaboradores, entendemos educação como formas de significação do mundo, socialmente reconhecidas e densamente institucionalizadas e inacabadas, em permanente estado de conformação, a partir de perspectivas temporais variadas que se entrecruzam.

Esse último aspecto é um dos pilares de sustentação da pesquisa de Antonádia Borges, uma vez que se recusa a dimensionar as experiências de moradores de BrasíliaDF a partir das intenções dos que planejaram a cidade. Borges oberva a perspectiva concreta, literalmente, de apagamento de rostos, vozes, vivências de pessoas que estão para além do Plano Piloto da cidade. Sem cair em fatalismos de discursos, supostamente bem intencionados, sobre a pobreza material de coletivos humanos que levariam as pessoas à suposta inanição de ação política (seguindo a linha de, por exemplo, LAHIRE, 2004; GUIMARÃES, 1998; ZALUAR, 1992; GONÇALVES; SPOSITO, 2002), a autora busca, através de etnografia, compreender a violência simbólica constante que moradores de cidadessatélite sofrem ao terem frequentemente as versões acerca de suas maneiras de existir ignoradas por moradores do Plano Piloto e agentes públicos. Em seu artigo, é possível compreender a experiência da construção

7. Vale lembrar a série de trabalhos questionando a estruturação das instituições educacionais e o papel do capital privado nesses processos, como, por exemplo, Cicourel \&t Kitsuse (1963), Young (1971) e Bowles \& Gintis (1976), também conhecidos como autores ligados à Nova Sociologia da Educação. 
de narrativas de si e dos outros, através de incursões dessas pessoas às escolas e à Universidade de Brasília. Desconfortos a partir dos quais o fluxo de pessoas de trajetórias distintas não são previamente dados como supostamente óbvios, mas construídos por meio de interlocuções da autora com as que desejam narrar suas vidas, tendo, como um dos marcadores identitários, ambientes de ensino institucionalizados.

As formas institucionalizadas de transmissão de técnicas e de suas diversas recepções pelos envolvidos também estão entremeadas por coletivos humanos que ensinam saberes fundamentais para a significação de sua vida objetiva, sem esquecer que o trabalho possa lhes ser valor ético e de entendimento de sua trajetória. Desse modo, Martina Ahlert buscou, por um lado, avaliar os efeitos e as percepções de participantes de duas associações de quebradeiras de coco babaçu de uma política pública, o programa Bolsa Família, e, por outro, a importância das autopercepções das mulheres que compunham aquelas associações das interfaces do programa, com continuidades e descontinuidades de procedimentos cotidianos nas suas vidas. A pesquisa de campo realizada em Codó, município maranhense, demonstra o papel narrativo da escola na definição de papéis, valores morais, e mesmo na gestão das emoções das quebradeiras no seu relacionamento com as múltiplas facetas do citado programa, principalmente no que tange às mediações burocráticas envolvendo índices prontos de níveis de escolaridade, por elas também manobrados. A autora nos ajuda a recuperar, indiretamente, algumas conhecidas perspectivas dos debates sobre as condições materiais objetivas de vida de pessoas com diversos níveis de escolaridade (LEITE LOPES; ALVIM, 1999). Suas interlocutoras estão envolvidas em relações através de escolas observadas como algo que não determina seu aprendizado, mas influencia a produção dos leques de possibilidades de recursos a serem acionados no âmbito de seus desejos e experiências.

Experiências essas que não podem ser, desde o artigo seminal de Lévi-Strauss (1975), e o provocativo de Edmund Leach (2010), operadas como se vivêssemos numa linha reta temporal, de fatos reproduzidos acriticamente num único sentido de possíveis causas e consequências. Voltando a Boas, populações com ou sem escrita não deixam de expressar, em tese, evidentemente, sua existência em vários sentidos demandados pelas suas relações. É possível, pensando dessa maneira, registrar medidas institucionais de políticas que sejam forasteiras ao coletivo ágrafo, em certos momentos, que o influenciem a partir de novos instrumentos de construção de ideias e de maneiras de expressá-las. As populações identificadas como indígenas no Brasil passaram, e passam, por inúmeros casos de subordinação involuntária a esse respeito, ao longo das modifıcações jurídico-administrativas do território do homem branco, por assim dizer. Purismos etnológicos dão lugar ao olhar crítico de Clarice Cohn e José Valdir de Jesus Santana de que as populações ameríndias sempre tiveram maneiras de educar e aprender, e continuarão a ter. Isso não significa que influências outras não venham a compor esses fenômenos sociais, posto serem construídos temporalmente, e não ignorando relações sociais para além das estabelecidas internamente a um coletivo específico. Os autores demonstram sua hipótese de que não seja possível hoje em dia entender os modos de conformação de identidades dessas populações sem levar em consideração as historicidades das 
práticas educacionais construídas, primeiro para elas, depois por elas e, finalmente, com elas e outros atores.

0 ensino de sociologia nas escolas brasileiras tem, do mesmo modo que os processos apontados pelos autores anteriores acerca da educação ameríndia, perspectivas de entendimento burocrático que rezam acerca de suas formas legais de atuação elementares. Recentemente, esses processos têm duas balizas mestras: o aumento de cursos de formação de professores de ciências sociais, e o centro desse fato se dar no âmbito do ensino privado e empresarial obedecendo às orientações liberais de competição nos mercados por clientes, ou seja, alunos. Amurabi Oliveira parte dessas duas premissas para avaliar o processo de expansão da formação daqueles professores, desde 2008, no estado de Santa Catarina. 0 autor, assim, busca escapar de leituras que procurem objetivar as leis ignorando os seus processos de interpretação e aplicação, no caso a regulamentação do ensino de sociologia e os que são autorizados a fazê-lo. Programas de governo são brevemente revisitados, assim como seus impactos aparentes nos quadros de professores de sociologia naquele estado, e quais valores morais operam a formulação legal da formação de professores.

Esses dados fornecidos e interpretados por Oliveira remetem, quase que inevitavelmente, à clássica obra de Pierre Bourdieu e Jean-Claude Passeron, Os Herdeiros (2009), uma vez que os autores também lidaram com processos de estruturação de valores morais por meio da regulação de critérios de ensino e aprendizagem. A pergunta "Quem herda o quê?" vem acompanhada de outra, "0 que se herda de quem?", e mostra a importância das pesquisas em sociologia e antropologia para avaliar o que está em jogo em diversos níveis de condições de possibilidade para a constru- ção de conhecimento escolar. A burocracia não amarra esse processo, contudo avaliza valores a serem aplicados por certos professores com níveis distintos de crítica, e outros a serem relativizados no processo de ensino, levando também em conta o de aprendizagem. Partindo da perspectiva de que situações plurais só podem ocorrer dentro de molduras de possibilidades socialmente constituídas e legitimadas, Philippe Masson, sociólogo francês, em A produção dos herdeiros, procura localizar a obra nas estruturas estruturantes de seu tempo, deslindando os critérios teóricos e metodológicos utilizados pelos dois autores. É possível, assim, que percebamos alguns traços de novidade nas propostas contidas no livro, e seus impactos imediatos entre os pesquisadores que compunham o campo de legitimação científica dos temas tratados em Os Herdeiros. Produção de conhecimento científico em sociologia em geral e em sociologia da educação em particular, debates sobre os significados da democratização do ensino na França, nos anos 1960, as escolhas teóricas dos autores, como elas aparecem no livro, e seus incômodos com os usos do conceito de "cultura de massas", são pontos-chave na carpintaria do artigo de Masson, e fundamentais para compreendermos as estratégias e as posições dos autores na produção de um conjunto de pesquisas que resultou em Os Herdeiros e, posteriormente, em A reprodução. A tradução desse artigo é oportuna a fortiori, por coincidir com a publicação tardia no Brasil, 50 anos depois de Os Herdeiros (2014), considerado, hoje, o refundador da sociologia francesa da educação, que influenciará, por conseguinte, as pesquisas nesta área numa escala internacional.

Se esta apresentação iniciou-se com Boas, e não convencionalmente por Durkheim, para falar em pesquisas em educação nas 
ciências sociais, chegamos à sua conclusão apresentando as linhas gerais de um animado debate sobre os escritos acerca do tema, daquele que fundou este campo específico de conhecimento, ao mesmo tempo em que balizava os princípios, limites e fronteiras da sociologia como ciência autônoma no "espaço de possíveis". Em 1992, as Jornadas de estudo sobre Durkheim e a sociologia da educação foram encerradas com uma mesa reunindo Michel Eliard, Pierre Bourdieu e Aïsse Kadri. O objetivo dos comentários mediados por Jean-Claude Filloux era avaliar em que termos os trabalhos de Durkheim acerca do tema educação continuavam atuais, e como, num segundo momento, de modo complementar, poderiam ser localizados na produção em ciências sociais. A dinâmica estabelecida foi a seguinte: os professores procurariam responder, em cerca de dez minutos, à questão que lhes havia sido previamente colocada, qual fosse, "o que quer dizer - agora, neste momento - ser durkheimiano quando se trabalha como sociólogo no campo da educação?” Em seguida, Filloux mediaria uma interlocução direta entre eles, complementada por último com perguntas e observações vindas da plateia. Os autores comentaram diversos temas levantados pioneiramente por Durkheim, trabalhados por ele em distintos níveis de profundidade, tais como educação e manutenção ou diminuição de desigualdades sociais, condições históricas de produção das percepções que as pessoas fazem de si mesmas, fenômenos objetivos e subjetivos da vida social, interpretações fiéis e heréticas de seus escritos, reivindicações de quinhões de seu espólio acadêmico e, por último, até que ponto é frutífero compreender, através de seus conceitos e suas definições, os processos educacionais da Argélia como ex-colônia francesa, mesmo quando Durkheim ainda era vivo e sobre nada a eles se referiu.
As perspectivas adotadas aqui não absolutizam nem estruturas estruturantes de (re)produção de formas de dominação, nem ideias fatalistas sobre lutas de classes cristalizadas e valores de dominantes e dominados amarrando/definindo o futuro de indivíduos e coletivos humanos. Nem otimismos exacerbados sustentados por leituras macrossociais universalistas em termos de valores morais, nem ausência das percepções dos participantes da vida social.

Tendo como ponto central os lugares e os referenciais, nos quais relações de hierarquia são construídas através da percepção e dos desejos e expectativas dos agentes sociais nelas envolvidos, este Dossiê traz autores em textos inéditos de pesquisas em andamento, além de duas traduções de textos consagrados. Eles não são, em alguma medida, sociólogos e antropólogos da educação, mas operam entendimentos de questões da vida social por eles traçadas através dos ambientes e referenciais socialmente reconhecidos por educação. Nesse sentido, nós, os organizadores do Dossiê, argumentamos que trabalhos empíricos ajudam a reler teorias e conceitos, a duvidar de metodologias, e a empregar criativamente tantas outras, observando que as pessoas vivem seus referenciais inacabados em permanente construção, sejam eles quais forem, tendo a educação como maneiras de expressá-los e constituí-los.

\section{Referências}

BECKER, H. S.; GEER, B.; HUGHES, E. C.; STRAUSS, A. Boys in white: student culture in medical school. New Brunswick: Transaction Books, 1984 (1961).

BENEDICT, R. Padrões de Cultura. Lisboa: Edições Livros do Brasil, 2005 (1934). 
BOAS, F. Antropologia. In: STOCKING Jr., G. W. (Org. e intr.). A formação da antropologia americana (1883-1911): Antologia/Franz Boas. Rio de Janeiro: Contraponto, Editora UFRJ, p. 323-340, 2004 (1907).

A mente do ser humano primitivo. Petrópolis: Vozes, 2010 (1938).

BOLTANSKI, L. Les cadres: la formation d'un groupe social. Paris: Éditions de Minuit, 1982.

BOURDIEU, P.; PASSERON, J. C. Los herderos: los estudiantes y la cultura. $2^{\text {a }}$. edición argentina. Buenos Aires: Siglo Veintiuno, 2009 (1964).

BOURDIEU, P.; BOLTANSKI, L. La producción de la ideologia dominante. Buenos Aires: Nueva Visión, 2009 (1976).

BOURDIEU, P. La distinction: critique social du jugement. Paris: Les Éditions de Minuit, 1979.

BOWLES, S.; GINTIS, H. Schooling in Capitalist America: educational reform and the contradictions of economic life. New York: Basic Books, 1976.

CALLON, M.; LASCOUMES, P.; BARTHE, Y. Acting in an uncertain world: an essay on technical democracy. Traduzido do francês. Cambridge: The MIT Press, 2011 (2001).

CICOUREL, A. V.; KITSUSE, J. I. The education decision-makers. Indianapolis: Bobbs-Merrill, 1963.

CUNHA, 0. M. G. da. Tempo imperfeito: uma etnografia dos arquivos. In: Mana, 10(2), p. 287-322, 2004.

DOUGLAS, M. Techniques of sorcery control in Central Africa. In: MIDDELTON, J.; WINTER, E. H. (Dir.). Witchcraft and sorcery in East Africa. London: Routledge \& Kegan Paul, p. 123-141, 1963.

How institutions think. Syracuse: Syracuse University Press, 1986.

ELIAS, N. Mozart: Sociologia de um gênio. Rio de Janeiro: Jorge Zahar Editor, 1994.

FLECK, L. Gênese e desenvolvimento de um fato científico: introdução à doutrina do estilo de pensamento e do coletivo de pensamento. Belo Ho- rizonte: Fabrefactum. Col. Ciência, Tecnologia e Sociedade, 2010 (1935).

FORACCHI, M. M.; PEREIRA, L. (Orgs.). Educação e sociedade: leituras de sociologia da educação. 7. ed. São Paulo: Editora Nacional, 1976.

GOLDE, P. (Ed.). Women in the field: anthropological experiences. Berkeley: University of California Press, 1986.

GONÇALVES, L. A. 0.; SPOSITO, M. P. Iniciativas públicas da redução da violência escolar no Brasil. In: Cadernos de Pesquisa, n. 115, p. 101-138, 2002.

GUIMARÃES, E. Escolas, galeras e narco-tráfico. Rio de Janeiro: Editora UFRJ, 1998.

LAHIRE, B. Sucesso escolar nos meios populares: as razões do improvável. São Paulo: Ática, 2004.

LANDES, R. A cidade das mulheres. 2. ed. Rio de Janeiro: Editora da UFRJ, 2002 (1947).

LEACH, E. Dois ensaios sobre a representação simbólica do tempo. In: Repensando a antropologia. São Paulo: Perspectiva, p. 191-209, 2010 (1953).

LÉVI-STRAUSS, C. História e etnologia. In: Antropologia estrutural. Rio de Janeiro: Tempo Brasileiro, p. 13-41, 1975 (1949).

LEITE LOPES, J. S. \& ALVIM, R. Uma autobiografia operária: a memória entre a entrevista e o romance. Estudos Avançados, 13 (37), p. 105-124, 1999. LÖWITH, K. 0 sentido da história. Lisboa: Edições 70, 1991 (1949).

MARTINS, C. B.; WEBER, S. Sociologia da educação: democratização e cidadania. In:

(Coord. geral); MARTINS, H. H. T. de S. (Coord. de área). Horizontes das ciências sociais no Brasil: sociologia. São Paulo: ANPOCS, Instituto Ciência Hoje, Discurso Editoral, Barcarolla, p. 129-201, 2010.

Estudos sociológicos sobre educação no Brasil (comentário crítico). In: MICELI, S. (Org.). 0 que ler na ciência social brasileira (1970-2002), volume 4. São Paulo: ANPOCS, Editora Sumaré, p. 439-455, 2002. 
MEAD, M. Sexo e temperamento em três sociedades primitivas. São Paulo: Perspectiva, 1988 (1935).

Continuities in cultural evolution. New Haven: Yale University Press, 1964.

MERTON, R. K. XVII. A ciência e a ordem social. In: Sociologia: teoria e estrutura. São Paulo: Mestre Jou, p.637-650, 1970a. (1968)

XIX. A máquina, o trabalhador e o engenheiro. In: Sociologia: teoria e estrutura. São Paulo: Mestre Jou, p.663-674, 1970b (1968).

MILLS, C. W. A nova classe média. 2. ed. Rio de Janeiro: Zahar Editores, 1976 (1951).

MOURA, M. M. Nascimento da antropologia cultural: a obra de Franz Boas. São Paulo: HUCIETC, 2004.

NEVES, C. E. B. 2002. Estudos sociológicos sobre educação no Brasil. In: MICELI, S. (Org.). 0 que ler na ciência social brasileira (1970-2002), volume 4. São Paulo: ANPOCS, Editora Sumaré, p. 352437, 2002.

OLIVEN, A. C. 0 desenvolvimento da sociologia da educação em diferentes contextos históricos. In: BIB, n. 34, $2^{\circ}$ semestre, 1992, p. 67-81.

PEREIRA, L. (Org. e intr.). Desenvolvimento, trabalho e educação. Rio de Janeiro: Zahar, 1967.

PINCH, T.; SWEDBERG, R. (Eds.). Living in a material world: economic sociology meets science and technology studies. Cambridge: The MIT Press, 2008.

SCHULTZ, T. W. 0 valor econômico da educação. Rio de Janeiro: Zahar, 1967.

O capital humano: investimentos em educação e pesquisa. Rio de Janeiro: Zahar, 1973.

SCHUMAKER, L. Africanizing anthropology: fieldwork, networks, and the making of cultural knowledge in Central Africa. Durham: Duke University Press, 2001.

SOUZA LIMA, A. C. de. Dossiê fazendo estado: o estudo antropológico das ações governamentais como parte dos processos de formação estatal. Revista de Antropologia, v. 55, p. 559-564, 2012.

STOCKING Jr., G. “Anthropology as Kulturkampf: science and politics in the carees of Franz Boas". In: The ethnographer's magic and other essays in the history of Anthropology. Madison: The University of Wisconsin Press, p.92-113. 1992a.

STOCKING Jr., G.. "Ideas and institutions in American Anthropology: thoughts toward a history of the Interwar Years". In: The ethnographer's magic and other essays in the history of Anthropology. Madison: The University of Wisconsin Press, p.114-177. 1992b.

A formação da antropologia americana: Franz Boas. Rio de Janeiro: Contraponto/EdUFRJ, 2004 (1999).

VELHO, G. Nobres \&t anjos: um estudo de tóxicos e hierarquia. Rio de Janeiro, Editora da Fundação Getulio Vargas, 1998 (1975).

VELHO, G. A utopia urbana: uma crítica da patología social. 2. ed. Rio de Janeiro: Zahar Editores, 1977.

WEBER M. Confucianisme et puritanisme. In: . Sociologie des religions. Paris: Gallimard, p. 379-410, 1996a (1915).

Avant-propos. In : Sociologie des religions. Paris: Gallimard, p. 489-608, 1996b (1920).

. From Max Weber: essays in Sociology. Oxford: Oxford University Press, 1946.

Os Letrados Chineses. In: . Ensaios de sociologia. Traduzido do inglês. 5. ed. Rio de Janeiro: Zahar, p. 470-501, 1982 (1915).

WHITE, H. Meta-História: a imaginação histórica do século XIX. São Paulo: EdUSP. 1992 (1973).

YANS-MCLAUGHLIN, V. Science, democracy, and ethos: mobilizing culture and personality for world war II. In: STOCKING JR, G. W. (Org.). Malinowski, Rivers, Benedict and others: essays on culture and personality. Madison: The University of Wisconsin Press, 1986. 
YOUNG, M. Knowledge and control: new directions for the sociology of education. London: Collier Macmillan, 1971.

ZALUAR, A. (Org.). Violência e educação. São Paulo: Livros do Tatu, Cortez, 1992. 